\title{
Research on Dilemma and Avoidance of Engineering Bidding
}

\author{
Xiaotian $\mathrm{Yu}^{1, \mathrm{a}}$ \\ ${ }^{1}$ Technical economy and management, Tianjin University of Technology, Tianjin, 300384, China \\ aemail: 2207534692@qq.com
}

Keywords: The lowest bid winning method; Comprehensive evaluation method; Unreasonable low bid; String behavior; avoid

\begin{abstract}
The purpose of the bidding mechanism is to give full play to the competitive system of the market, So that market participants in the equal and fair conditions of the survival, and the resources are most appropriately allocated. The evaluation of bidding is the most important part of the bidding mechanism, is the core of bidding work. At present, there are two kinds of bidding methods in China. First, the lowest bid winning method, in the actual advance easily lead to the winner of the curse of the phenomenon. The other is a comprehensive evaluation method, but a great increase in the bidders between the string of behavior, that is, the emergence of price cartels. For the current two kinds of evaluation methods caused by the reality of the problem to find their methods to avoid.
\end{abstract}

\section{Introduction}

China's "tender law" is to adjust the tender activities currently. Protect the national and social public interests and the tender interests of the parties to the legitimate interests of the project to improve the economic efficiency of the market to ensure the final quality of the project. Bidding is the essence of competition, through competition to eliminate the tender and the bidder's information asymmetry, reduce the bidders information rent, so as to choose the best quality contractors.

At present, there are two kinds of bid evaluation methods at home and abroad, one is the lowest bid winning method, and the other is the comprehensive evaluation method[1] .The lowest bid method is a kind of bidding method which is widely adopted after the promotion of the pricing model. It is a kind of construction project bidding and management method which is universally applicable[2]. But the implementation of our country at this stage of the assessment of the lowest bid winning method [3]. In practice, is easy to induce "winners curse" strange phenomenon. That is, low offer, low quality, low credibility of the bidder won the bid, Adverse selection also leads to moral hazard, Low-quality bidders tighten the contractor, the construction phase of the contractors continue to rip, resulting in the risk of unpaid contractors investment.

In the large-scale construction of the tender, the comprehensive evaluation method is a more than the lowest bid method more in line with the more applicable evaluation method[4]. It can fully reflect the intention of the tenderer. However, the use of a comprehensive evaluation method has greatly increased the bidders between the string of the possibility of behavior. Because the cost of the string method of the comprehensive evaluation method is less than that of the lowest bid winning method, the gain of the string is higher and the winning probability is higher. Thus, the formation of a dilemma in the tender situation in China under the situation.

That is, regardless of what kind of bidding method, the contractor will lose the investment stage of the investment control and can’t play the original intention of bidding mechanism. 


\section{Literature References}

In recent years, in the bidding process of the project in China, the "winners' curse" caused by the lowest bid winning method, the study of the curse of the winners mainly includes: joint bidding, information sharing and learning. Wang Zhiyu who proposed to solve the lowest bid method is mainly focused on information centralized management, engineering insurance and security and so on[5].Xiao Xianwen proposed for the lowest bid method is to strengthen market supervision, improve the construction of laws and regulations, the establishment of corporate credit system, improve the risk transfer system[6].

Ren Hong According to the theory of signal game, it is pointed out that the cost of the string is the penalty of the string and the cost of the bidder's supervision is the factor that affects the behavior of the string[7]. Wo Chenliang et al established the prisoner's dilemma Model to analyze the way in which the expected income of the string is controlled to prevent the occurrence of the string's behavior. By changing the string was found to investigate the probability of the string of the proceeds, such as punishment to prevent the occurrence of bad behavior[8]. Li Yanfeng proposed to measures to resolve the phenomenon of surround marks in bidding and bidding that the Government to establish a tender business integrity reward and punishment mechanism, the establishment of the proposed project leader to participate in the opening system, the expert judges to adopt a "two-step" approach and other methods[9].

This article will be the assessment of the lowest bid winning method and the comprehensive evaluation method caused by the nature of the phenomenon to solve the problem. By the assessment of the lowest bid winning method caused by the "winner of the curse" strange phenomenon, By the comprehensive evaluation method caused by the price of cartels, from the nature of the search for their way to avoid.

\section{Unreasonable low - cost bidding behavior to avoid:}

\section{1status quo:}

If the lowest bid winning method is used for the evaluation, bidders are required to make a trade-off between prices that are low enough to ensure that profits and prices are high enough to ensure competitiveness, Bidders will also face a dilemma: Low offer means that the greater the probability of winning, the less profit; high offer means that the smaller the probability of winning, the greater the profits. The best bidder is to win the bid at a higher price, but it is often counterproductive.

Unreasonable low price will make the contractor in the construction phase to find ways to get the original contract price outside the contract revenue compensation. In this case, the bidder should consider only the winning problem. This contractor in order to obtain the bid in the bidding stage at the expense of a certain profit in the construction phase by cutting corners to reduce costs, change, claims, price adjustment and other strategies to obtain the original contract price of income compensation behavior will make the contractor on the surface to choose a low Price, but actually have to pay a higher price, that is, the employer was "curse".

\subsection{Motivation:}

\subsubsection{Single focus on business volume}

Under the state-owned property system, the loss of the enterprise is not borne by the individual directly, The moral hazard of some officials of state-owned enterprises is reflected in the bidding 
price, On the surface seems to increase the amount of business, but in fact lead to loss of business, damage the interests of taxpayers.

\subsubsection{Hold the bidder and get the extra price}

The bidder has the tendency to lower the price or even lower than the cost in the lowest bid price. In order to win the project, the bidder in the tender offer again and again down their own prices. When the contract negotiations are signed, the contractor may also ask the winning bidder to make further price concessions[10]. When the contractor in the construction phase found unable to continue in accordance with the original contract, it will change the original contract by the state.

When the contractor submits an additional budget to the contractor, the contractor faces two options, either to stop the performance of the contract or to make an additional investment to ensure the smooth progress of the project. Due to the large investment in the construction project, it can not easily stop the contract. If the contract is closed for the parties to the contract may cause more difficult to deal with, so the contractor will often choose to additional investment.

\subsubsection{Manufacturing status changes, later to be compensated}

Unreasonable low-cost bidding is the driving force in the construction phase can be based on the actual construction and the contractor around the price to negotiate again, Such cases bidders once successful in the construction phase tend to break the original state of the contract. To achieve a new balance, through the change or visa, price adjustment, claims, etc. to compensate, This is bound to change the initial contract under the corresponding contract price, to a new contract price[11], In such circumstances, the bidder has sufficient incentives to take opportunistic behavior, that is, by taking other means after the additional investment to make up for the bid to reduce the price of the loss.

\subsection{Precautionary approach to unreasonable low-priced bidding behavior}

\subsubsection{Inverse selection regulation caused by low bid}

The adverse selection caused by the low bidding behavior in the bidding stage can be resolved by the following two aspects, On the one hand, the bidders can evaluate the relevant information of the bidding enterprises through the special evaluation committee, and at the same time, through the communication of their suppliers, relevant government departments and other consulting firms, to alleviate the information asymmetry to the greatest extent. Therefore, the tenderer should be as much as possible to refine each of the contents of the tender documents, to ensure that the bill of quantities integrity and correctness, To eliminate potential passive factors in advance, for each bidder to analyze whether it is lower than the cost.

On the other hand, the bidder can use two-stage evaluation method; Through the bidder's enterprise size, personnel quality, mechanical quality, engineering experience to establish the first round of the finalists, and then through the relevant technical assessment to determine the final bidder.

\subsubsection{Moral Risk Management Caused by Low Bidding}

The governance of moral hazard can be "two-pronged" from both incentives and constraints. Incentives allow the contractor to have no moral hazard, and the constraint mechanism allows the contractor to have no moral hazard action.

On the one hand, the tenderer must ensure that the bidder has a certain profit margins and reduce the motive of the moral hazard behavior of the tenderee;

On the other hand, The tender to ensure that their legitimate interests are inviolable by adding restrictions in the contract and severe penalties for breach of contract, so that contractors can not default, Change the cost income of the successful bidder's moral hazard, and reduce the moral 
hazard behavior of the successful bidder. The project guarantee in the actual project is to ensure that the contractor is contracted and the independent third party is bound to act in the construction process to increase the binding performance of the contract[12].

\section{Protection of string behavior}

\section{1status quo:}

Construction project bidding between the bidder in the horizontal string standard is to limit the exclusion of other bidders, A private agreement between the Group, The agreement undermines the competitive bidding mechanism to play, its fundamental purpose is to seek their own interests.

\subsection{The motive:}

The motive for generating a string of behavior is that the interest that the string participant considers to be used for nonproductive interest-seeking activities is greater than the benefit of the productive interest-seeking activity, It will stimulate the bidders to generate opportunistic psychology, to stimulate their participation in the cartel. That is, the root of the cross string between the bidders is that the proceeds from the implementation of the string are greater than the cost.

\subsection{String behavior check path}

Whether the bidder is involved in the string depends on the string of income and the benefits of normal competition to bring the size of the proceeds, Only the former income is greater than the latter income, the bidders will risk the risk of participating cartels. On the other hand, bidders by comparing the cost of string standard and the cost of normal bidding, Only the former cost less than the cost of the latter, people would run the risk involved in bidding cartel. The price cartel - string behavior can reduce the string behavior by reducing the string yield or increasing the cost of the string. In order to prevent the collusion caused by the behavior of the string, the client must develop some incentive policies so that the betrayer gets more income than the conspiracy group, the betrayer has the power to betray the conspiracy[13].

\subsubsection{Reduce the string income}

The construction of information asymmetry between bidders is one of the effective ways to prevent the occurrence of string standard behavior, When there is information asymmetry between the bidders, each cartel members will hold even if the betrayal of the organization, it will not be equipped with the mentality of discovery, On the basis of understanding the various members of the tender offer, Take a certain strategy to betray the organization to maximize the personal interests of the cartel, rather than the largest interests of the organization. Therefore, the mechanism to prevent the behavior of the string should focus on the information asymmetry between the bidders. Specific measures can be implemented such as: Increasing the number of bidders to increase the cost of the string so that the leader can not afford to voluntarily give up the string. The increase in bidders will increase the difficulty of planning, communicating, negotiating, coordinating each other's behavior and dividing the string's revenue. The increase in the number of cartel members will make the cartel more unstable, the reason is that the increase in the number of transfers means that the increase in payment and communication costs increase, so increase the number of bidders is conducive to prevent collusion. 


\subsubsection{Increase the cost of string}

(1)Cut off the means of information transmission to reduce prisoner cooperation opportunities

In the prisoner's dilemma, two interrogated prisoners were unable to communicate with each other, Need to guess each other between the other's decision-making, And then according to their own situation must be in their own risk minimization and profit maximization between the trade-offs, As the prisoners can't communicate between the prisoners from this heart, which to some extent affected the stability of the prisoners Union organization, But if the prisoners have the opportunity to carry out information transmission, then the prisoners are likely to establish an offensive and defensive alliance, Therefore, between the tender, the tender set up the bidding mechanism to cut off the information between the bidders, or let the bidders can't understand each other who is the other.

Before bidding, there are many possible opportunities for bidders to contact, such as on-site purchase of tender documents, survey site, prequalification, etc., Therefore, through the implementation of the method, for example, Online tender documents or Using different time for potential bidders to survey the scene to cut the bidders information transmission to reduce the bidders before the cooperation opportunities.

(2)Set up a "waiver system" to encourage the string to surrender

The liberalization system in developed countries lies in the establishment of a prisoner's dilemma, Only the first few surrender of the string of bidders who can receive preferential treatment that is free to avoid the system, so that people involved in collusion between the formation of "people in the nest" phenomenon, Leading to mutual distrust and suspicion, the formation of a phenomenon of competing for surrender, and ultimately to achieve the purpose of the collapse of the joint. The purpose of setting up a waiver system is to reduce or even eliminate penalties for part of the surrender, in order to obtain the discovery of collusion bidding. In summary, through the string of behavior caused by the consequences of the avoidance analysis shown in Figure 1.

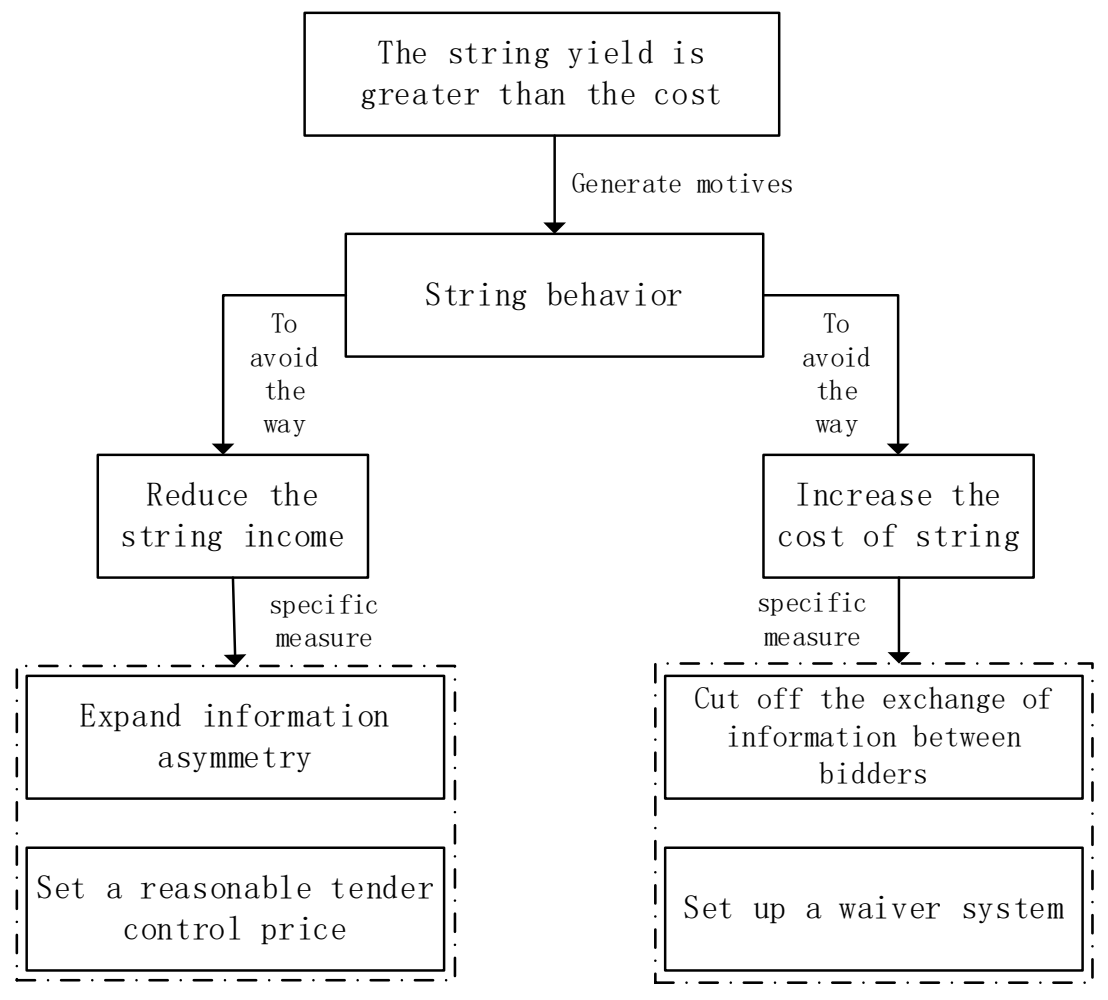

Figure 1 A path to avoid the behavior of the string 


\section{Conclusion}

In view of the current dilemma of bidding, The lowest bid price is likely to cause the winner to curse the phenomenon, and the use of comprehensive assessment for the bidder between the string standard to provide a breeding ground. This article for the winner of the curse caused by the phenomenon caused by the phenomenon, To avoid the adverse selection to take to increase information disclosure, two-stage tender, To avoid moral hazard to take incentives and constraints of the means. On the string behavior, respectively, from the reduction of string income, increase the behavior of string to avoid.

\section{References}

[1]Li tao .Comparison between the lowest price method and the comprehensive evaluation method[J]. Value Engineering, 2014(2):72-73.

[2]Song meng. An Analysis of the Problems and Countermeasures in the Implementation of the Lowest Bidding Method in China[J]. Hydropower station design, 2016, 32(1):91-93.

[3] Pan haimei. An Analysis of the Practice of Evaluating the Lowest Bidding Method[J]. Building economy, 2006(9):92-94.

[4] Zhang Lingyun. Research on Comprehensive Evaluation Method of Engineering Construction Based on Eigenvector and TOPSIS[J]. Journal of Engineering Management, 2013(5):78-82.

[5]Wang Zhiwu, Chang Jianying. Analysis and application of the lowest bid method [J]. Journal of North China Institute of Water Conservancy and Hydroelectric Power (Social Science Edition), 2005, 21(3):73-76.

[6] Xiao Xianwen. The problems and countermeasures in the application of the lowest bid winning method in our country [J]. Shanxi architecture,2010, 36(33):272-273.

[7] Ren Hong, Zhu Lianbo. Signal Game Analysis of String Behavior in Engineering Bidding [J]. Journal of Civil Engineering, 2007,07: 99 103+110.

[8] Wei Chen Liang, Ye Meng Li, Zhao Yong. The mechanism analysis and coping strategy of string standard [J]. Chinese government procurement, 2013,12: 74 76.

[9] Li Yanfeng. How to resolve the bidding process in the process of bidding around the standard and post - standard supervision measures and recommendations [J]. Tender and tender, 2016(9):16-17.

[10] Wu Jiaming. Research on transaction cost control in project construction [D]. Beijing: Beijing Jiaotong University. 2008.

[11] Yin Hang. A Study on Settlement Disputes Based on Incomplete Contract Theory: A Perspective of Contract State Compensation [D]. Tianjin: Tianjin University of Technology. 2015.

[12] Dan xiaomei, Study on the construction bonding system in China[M]. China Construction Industry Press, 2012.

[13] Yan Zou-xian, Shang Qiu-fen. A review of the research on the incentive mechanism of collusion collusion [J]. Journal of Shijiazhuang University of Economics, 2008,(03): 57 61. 